\title{
Percepción de las noticias falsas en universitarios de Portugal: análisis de su consumo y actitudes
}

\author{
Perceptions about fake news in Portuguese higher \\ education students: An analysis of \\ consumption and attitudes
}

\author{
João Figueira; Sílvio Santos
}

Cómo citar este artículo:

Figueira, João; Santos, Sílvio (2019). “Percepción de las noticias falsas en universitarios de Portugal: análisis de su consumo y actitudes". El profesional de la información, v. 28, n. 3, e280315.

https://doi.org/10.3145/epi.2019.may.15

Artículo recibido el 29-12-2018

Aceptación definitiva: 06-05-2019

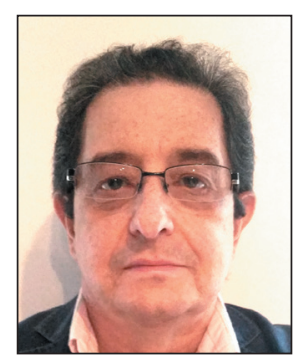

João Figueira $\square$

http://orcid.org/0000-0002-2344-9789

Universidad de Coimbra

Faculdade de Letras

Largo da Porta Férrea.

3004-530 Coimbra, Portugal

jotajotafigueira@gmail.com

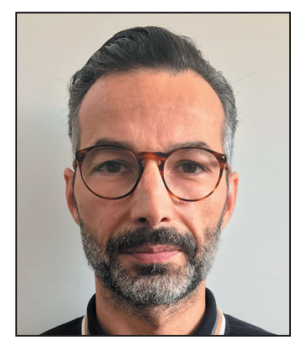

Sílvio Santos

http://orcid.org/0000-0002-6208-7311

Universidad de Coimbra

Faculdade de Letras

Largo da Porta Férrea.

3004-530 Coimbra, Portugal

silvio.santos@fl.uc.pt

\section{Resumen}

Las noticias falsas, también conocidas como fake news, representan una parte significativa de uno de los problemas más complejos en el marco de la circulación de información en la sociedad contemporánea: la desinformación. A pesar de no ser un fenómeno nuevo, su importancia y las posibles consecuencias sociales y políticas de su difusión por internet han sido ampliamente discutidas, especialmente, en los últimos dos años. Los jóvenes son uno de los grupos más expuestos a esta realidad, si tenemos en cuenta la presencia de la tecnología de la comunicación en su día a día. En este artículo revisamos la bibliografía relacionada con la desinformación y analizamos la ya larga relación entre las noticias falsas y el periodismo, con especial hincapié en las particularidades de la situación actual. Siguiendo el método cuantitativo, hemos utilizado un cuestionario para analizar la percepción de 602 jóvenes estudiantes portugueses de entre 17 y 25 años sobre las noticias falsas. Los resultados revelan que se trata de un grupo habituado a consumir información online, y que ya ha entrado en contacto con lo que consideran noticias falsas. Sin embargo, existen diferentes concepciones -en ocasiones, equivocadas - de la expresión fake news. Así pues, este estudio subraya la importancia de la alfabetización mediática y, más concretamente, de la credibilidad, de contrastar la información online y de la actual dinámica de la información.

\section{Palabras clave}

Fake news; Noticias falsas; Desinformación; Consumo de información; Actitudes; Percepciones; Opiniones; Jóvenes; Estudiantes; Enseñanza superior; Portugal.

\section{Abstract}

Fake news constitutes a significant part of one of the most complex problems that affect the flows of information in contemporary society: disinformation. Although this is not a recent phenomenon, the political and social consequences of

Financiación

Los autores han tenido el apoyo de la FLUC y del CEIS20 (UID/HIS/00460/2019). 
the spreading of fake news on the internet have been thoroughly discussed in the last couple of years. Currently young people are the group with greater exposition to this reality due to the prevalence of communication technologies in their daily lives. On this article we review the literature on disinformation and analyse the longstanding relationship between false news and journalism, focusing on the particularities of the present situation. Using quantitative methodology, we conducted a survey to analyse the perceptions regarding fake news of 602 students (17-25 years-old) from higher education in Portugal. Our findings reveal a group that is clearly used to getting information online and has already contacted with fake news. However, different conceptions about what is fake news coexist, including erroneous ones. Hence, this study reaffirms the importance of media and information literacies, particularly the importance of raising awareness on credibility assessment, fact checking and the particularities of the information flows.

\section{Keywords}

Fake news; Disinformation; Information consumption; Attitudes; Perceptions; Opinions; Young people; Students; Higher education; Portugal.

\section{Introducción}

Los posibles efectos de la desinformación divulgada a través de internet durante las últimas elecciones en EUA y, más recientemente, en Cataluña, han provocado que las noticias falsas y la desinformación ocuparan el centro de las agendas política y científica. El propio espacio público ha acogido la discusión sobre este fenómeno. El Collins Dictionary, tras comprobar un aumento del 365\% de su uso online, eligió fake news como la expresión del año 2017.

Sin embargo, ha de observarse que aunque la discusión acerca de las noticias falsas y una más amplia ola de desinformación se hayan intensificado en la actualidad, el fenómeno no es nuevo. El surgimiento de la mentira enmascarada como noticia en la prensa está documentado ya desde el siglo XIX, aunque en aquel entonces la sociedad no la hubiera conocido como tal. La llegada de la expresión fake news al dominio público se produjo tras el éxito de los programas televisivos satíricos (Tally, 2011; Love, 2007) en el cambio de milenio ${ }^{1}$.

Entonces, ¿qué ha cambiado en el contexto actual? ¿Qué causa que la situación sea tan preocupante hoy en día? ¿Por qué motivo hablamos de ello como si fuera algo inédito? Al no ser ni la desinformación ni las noticias falsas dos fenómenos completamente nuevos en la historia del periodismo y de la información, la relevancia y pertinencia en su discusión se justifican con el hecho totalmente nuevo de vivir en una era en la que las fuentes de producción informativa se han multiplicado y han pasado a tener a su alcance grandes audiencias, lo que significa que el potencial de divulgación y propagación de noticias falsas es hoy mayor que nunca (Southwell; Thorson; Sheble, 2018).

Así pues, ante esta situación, queremos analizar cómo ven este fenómeno algunos de los miembros más activos de este nuevo tejido informativo: jóvenes y adultos jóvenes, estudiantes de enseñanza superior. Nuestra interrogación se sostiene en el foco que en los últimos años se ha puesto sobre el desarrollo digital y sobre la permanente conectividad y conexión a las redes sociales de este grupo. Entonces, ¿cómo se enfrentan los jóvenes adultos, estudiantes de enseñanza superior en Portugal, a estas noticias falsas?

En este artículo nos hemos propuesto realizar una reflexión acerca de la presencia de las noticias falsas en la sociedad, y dirigimos nuestra atención hacia los jóvenes adultos recurriendo a una metodología cuantitativa. Para contextualizar esta realidad, que forma parte de un contexto más amplio que Wardle y Derakhshan (2017) caracterizan como desorden informativo, hemos partido de una revisión bibliográfica que enfatiza la carga ideológica de los medios de comunicación, que documenta la ya larga presencia de las noticias falsas en dichos medios, y que analiza las condiciones particulares que hoy hacen este fenómeno tan relevante y amenazador dentro del actual ecosistema mediático.

Sólo nos centraremos en una parte de esta compleja red: las noticias falsas. Aunque nuestra atención gire en torno al periodismo, nuestra observación abarca necesariamente prácticas no periodísticas como, por ejemplo, las que cualquier ciudadano pueda ejercer en las redes sociales, debido al potencial efecto - ya sea al compartir, o como fuente de información de los medios tradicionales o del público al que llegan- que tales contenidos pueden tener.

\section{Periodismo y manipulación}

Sin que lo supieran, Hermann Tertsch y Berna González Harbour relataban en la edición del 29 de diciembre de 1989 de El país un episodio que Ramonet describiría como "el engaño más importante desde la invención de la televisión" (Ramonet, 1990, p. 56). Los periodistas del diario español enviados a Bucarest escribían que,

"en la ciudad rumana de Timisoara, el ejército ha descubierto cámaras de tortura en las que sistemáticamente se desfiguraban con ácidos los rostros de disidentes o líderes obreros para evitar que los cadáveres fueran reconocidos en caso de que se encontraran"2 (Ramonet, 1990, p. 57).

Y “¿Cómo saber el número de muertos?”, preguntaba el enviado especial de la Agencia France Press, en un texto publicado el 23 de diciembre de 1989 en el diario Libération: 
"Los conductores de los camiones que transportaban metros cúbicos de cuerpos, fueron abatidos por una bala en la nuca por la policía secreta para eliminar todo testigo" (Ramonet, 1990, p. 57).

Estas y otras noticias similares publicadas por los enviados especiales de varios medios europeos a Rumanía dejaron en shock a la opinión pública, y empujaron al entonces ministro de Exteriores francés, Roland Dumas, a realizar declaraciones totalmente idénticas a las que hemos oído más recientemente para justificar los bombardeos en Siria y a las que anteriormente se habían realizado durante la invasión de Irak:

"No se puede asistir como espectador a tal masacre" (Ramonet, 1990, p. 58).

Sólo que, de igual modo a lo que sucedió con la intoxicación mediática, en 2003, a propósito de la presencia de armas de destrucción masiva en Irak - que hoy sabemos que fue una maniobra de manipulación de la información (Lewandowsky et al., 2013) - , se supo después que, en el caso de Timisoara, los relatos de los medios de comunicación no se correspondían con la realidad. Todo se resumió en una representación que empezó transmitiendo el hallazgo de una zanja con más de cuatro mil cadáveres, víctimas de tortura por parte de la policía secreta del dictador Nicolae Ceausescu. Los cuerpos existían, los fotografiaron y exhibieron por televisión, pero habían sido desenterrados de un cementerio en el marco de una acción de propaganda que tenía como objetivo acabar, como sucedió unos días después, con Ceausescu y su mujer, que fueron ejecutados.

Las maniobras de manipulación y desinformación también están presentes en los conflictos en Kosovo, en la Primera Guerra del Golfo (ambos en la década de 1990 del siglo pasado), en Afganistán (en 2001) y más recientemente en Siria, por indicar únicamente algunos de los casos más recientes y conocidos que marcaron la agenda mediática a escala global, y que confirman la antigua máxima de Esquilo: "La verdad es la primera víctima de la guerra".

¿Dónde estuvo en este caso y dónde está hoy, finalmente, el “saber prudencial” que Galdón-López (2001, p. 258) atribuye al ejercicio del periodismo, y que Kovach y Rosenstiel caracterizan como skeptical knowing (2010), como método de comprobación de la información?

Tanto la sociedad como la propia clase periodística esperan un compromiso con la verdad, lo que conlleva el respeto y el cumplimiento permanentes de los procedimientos y métodos de comprobación de la información que se produce y transmite. Sin embargo, a diario la situación parece cada vez más nublada, no sólo para los periodistas, sino sobre todo para los ciudadanos, quienes a menudo no comprenden las mecánicas de la producción y circulación de noticias, y que están cada vez más aplastados por la cantidad de información disponible.

Sabemos que en las sociedades actuales de la superabundancia informativa, ésta surge muchas veces "contaminada con mucha mentira, con mucha falsedad, con mucha ocultación", como nos advierte Ignacio Ramonet en el prólogo de la obra de Pascual Serrano, Desinformación: Cómo los medios ocultan el mundo (2009, p. 14). Especialmente, cuando la principal estrategia en la sociedad de la desinformación parece ser llamar la atención en vez de informar, como sostiene Otte (2010). Por eso se empezó a hablar de infoxicación — “infoxicación 2.0”, tal como le llama Benito-Ruiz (2009)—, una época de saturación que se caracteriza por la prevalencia del infotainment, por la explotación de temas altamente atractivos, por la pérdida de la preocupación deontológica periodística y por una producción centrada en la viralización (Romero-Rodríguez; Casas-Moreno; Caldeiro-Pedreira, 2018, p. 75-76).

Sin embargo, considerar el periodismo como un vehículo de falsedades deliberadas nos obliga a retroceder a mucho antes de Timisoara. Y aunque existan registros de usos anteriores de la prensa con el objetivo de manipular a la opinión pública, hemos de centrarnos en los casos que surgen específicamente bajo el manto de la credibilidad periodística. Como explica Love (2007, p. 34), a pesar de que en la prensa británica del siglo XVIII ya se había encontrado información engañosa, fue en el siglo XIV, tras el surgimiento del sector de la prensa y la introducción de nuevas tecnologías, cuando se establecieron las noticias falsas hasta el punto de volverse un problema real. Great Moon Hoax fue el caso más notorio, en el inicio del periodismo moderno y de la penny press ${ }^{3}$. A pesar de que el público y los periodistas de aquel entonces habían proclamado a la verdad como principio y fin del periodismo, sabemos que en la época en la que la penny press quería establecerse no todo lo que se leía en esa nueva prensa era verdad (Thornton, 2000). El público estaba también aprendiendo a lidiar con esta evolución de la prensa, que adoptaba estrategias para popularizarse.

Como ya se ha indicado, durante el siglo XX las noticias falsas y la desinformación no desaparecieron de los medios de comunicación de masas, sino que se volvieron especialmente evidentes en períodos de conflicto. Sin embargo, en esas circunstancias, las empresas y los periodistas se erigieron en bastiones de la verdad. En una encuesta realizada en EUA en 1999, todos los periodistas entrevistados afirmaron que la primera obligación del

\author{
Durante el siglo XX las noticias falsas y \\ la desinformación no desaparecieron de \\ los medios de comunicación de masas, \\ sino que se volvieron especialmente evi- \\ dentes en períodos de conflicto
}

periodismo es la verdad: "getting the facts right" (obtener los hechos correctos) (Kovach; Rosenstiel, 2004, p. 67-68). Los periodistas saben que están comprometidos con la verdad. Y, a pesar de la desconfianza que existe, la gente también reconoce ese ethos. 
Así pues, la manera en la que las sociedades democráticas modernas se han desarrollado está íntimamente relacionada con el papel de los medios de comunicación y del periodismo en la producción de conocimiento. Cuando a mediados del siglo XX Robert Park conceptualizó la noticia como forma de conocimiento, se anticipó a la visión que décadas más tarde Kovach y Rosenstiel propondrían al defender que el propósito principal del periodismo es proporcionar a los ciudadanos la información que necesitan para ser libres y capaces de gobernarse a sí mismos (Kovach; Rosenstiel, 2004, p. 16-23). Por el contrario, un mundo sin periodismo es un mundo donde sobra espacio para la propaganda (McChesney; Nichols, 2010).

\section{Delimitar las noticias falsas en el seno de la desinformación democrática}

La tecnología ha servido en todas las épocas para acelerar el tiempo del mensaje informativo, lo que significa que la velocidad y los medios para propagar la verdad son idénticos a los que se pueden movilizar para transmitir la mentira. "Las imágenes de la marea negra del Golfo eran, en la mayoría de los casos, las de precedentes catástrofes" recuerda Woodrow (1996, p. 49) y, sin embargo, subraya que para el ciudadano común la información era verdadera porque la había visto por televisión. Así sucedió, entre muchos otros casos, con los cadáveres de Timisoara, un ejemplo que nos conduce al pensamiento de Breton:

“manipular consiste en construir una imagen de lo real que tenga la apariencia de ser la realidad” (Breton, 2002, p. 22). Por lo demás,

"la primera fase de cualquier manipulación consiste, precisamente, en convencer al interlocutor de que es libre" (Breton, 2002, p. 25).

La manipulación como fenómeno que tiene la intención de construir artificialmente una determinada realidad se inscribe, pues, en la noción más amplia de desinformación propuesta por Vladimir Volkoff: la desinformación consiste en la

"manipulación de la opinión pública con fines políticos a través de información tratada mediante procedimientos ocultos" (Volkoff, 2000, p. 31).

Ahora bien, cuando en la actualidad hablamos de desinformación, estamos definiendo una realidad muy diferente a la retratada por Volkoff. No es posible pensar el ecosistema mediático actual sin considerar la desinformación como un elemento endógeno e intrínseco, tal como explican Aguaded y Romero-Rodríguez: en medio de la sobrecarga informativa existente, es imposible consultar información sin entrar en contacto con esa desinformación (Aguaded; Romero-Rodríguez, 2015, p. 48). Y la realidad es muy diversa y compleja:

"este ecosistema ha creado vicios propios de manipulación y desinformación —como el clickbait, las fake news, el cat-fish, el sockpuppeting, el astroturfing y la fabricación de contenidos-, a la vez que ha aumentado exponencialmente las estratagemas tradicionales: falacias, eufemismos, disfemismos, cherry-picking, distracción y globos sonda, entre otras" (Romero-Rodríguez; Valle-Razo; Torres-Toukoumidis, 2018, p. 264).

Así pues, este es el contexto del cual forman parte, como siempre lo han hecho, las noticias falsas. Tal como alerta la Comisión Europea, las noticias falsas de hoy sólo son una parte del problema más amplio de la "desinformación" (European Commission, 2018).

Autores como Wardle y Derakhshan (2017, p. 5) y Sullivan (2017) defienden, del mismo modo, que la expresión "noticias falsas" no abarca el problema en su globalidad, además de ser una expresión que los agentes políticos han instrumentalizado. Pero es esta pequeña parte del problema en la que nos centramos.

No es fácil encontrar una definición consensuada de las fake news, tal como advierten Romero-Rodríguez, Valle-Razo y Torres-Toukoumidis (2018). Allcott y Gentzkow hablan de las noticias falsas como piezas periodísticas intencionada y conscientemente falsas que pueden indu-
El periodismo vive actualmente una cri- sis que puede verse desde tres enfoques: profesional, económico y de confianza cir a los lectores a un error (Allcott; Gentzkow, 2017)4. Aquellas a las que Tandoc, Lim y Ling (2017) atribuyen una clara intención de engañar. De hecho, las noticias imprecisas e incompletas existen desde siempre. Siempre ha habido engaños y errores, y casi siempre se corrigen. Pero aquí hablamos de otra cosa. Tal como explican Romero-Rodríguez, Valle-Razo y Torres-Toukoumidis (2018, p. 270) la noticia falsa es una pieza que, por lo general, reúne tres características:

- elementos estéticos similares a los de la información periodística;

- adopción de formatos narrativos propios del periodismo;

- intencionalidad desinformativa.

En este conjunto de características se engloban, pues, diferentes tipos de fake news con diferentes grados de facticidad y de intención de engañar: noticias satíricas, parodias de noticias, fabricación de noticias, infopublicidad y propaganda (Tandoc; Lim; Ling, 2017, pp. 141-148; Romero-Rodríguez; Valle-Razo; Torres-Toukoumidis, 2018, pp. 265-269) ${ }^{5}$. 


\section{4. ¿Qué sostiene al nuevo desorden informativo?}

Para comprender lo que difiere en la actualidad, primero conviene que subrayemos dos factores estructurales que se relacionan entre sí:

- crisis de confianza en los medios (Nielsen; Graves, 2017; Nielsen, 2016);

- aparición de un ecosistema mediático nuevo y más complejo.

Como explica Nielsen (2016), el periodismo vive actualmente una crisis que puede verse desde tres enfoques: profesional, económico y de confianza. Y aunque los retos a los que se enfrenta la profesión vengan parcialmente de antaño, la situación se ha agudizado en el siglo XXI (Fuller, 2010). El éxodo de los lectores hacia la Web y la transformación de los flujos publicitarios estaban acabando con los medios de comunicación que funcionaban hasta este momento. Estas dos dimensiones, la del papel del periodista en la era del contenido generado por el usuario y la de la lentitud de la adecuación del modelo de negocio a las nuevas condiciones, ayudan a entender la complicada situación a la que han llegado muchas de las empresas informativas, que se han visto en la necesidad de reducir las plantillas y embarcarse en una frenética producción en actualización constante, además de luchar por formas de financiación eficaces en un contexto en cambio. Nada de esto ayudó a combatir la desconfianza generalizada que ya existía con relación a los medios ${ }^{6}$. La gente cuestiona las relaciones entre las estructuras de poder, particularmente entre los medios y la política, y duda de la forma en que éstas actúan en favor del interés público.

La realidad que hemos retratado anteriormente, en la que las noticias falsas surgían disimuladas en el seno del periodismo, o abiertamente satirizadas en la televisión, conlleva una realidad mediática con contornos mucho más nítidos. Los flujos de transmisión resultaban de relaciones de poder muy claras en las que eran perfectamente identificables el emisor y el receptor. Sin embar-

\section{La gente cuestiona las relaciones entre las estructuras de poder, particularmen- te entre los medios y la política, y dudan de la forma como éstas actúan en favor del interés público}

go, con el fin del monopolio de los medios de comunicación, algo ha cambiado. La revolución del contenido generado por el usuario que trajo la web 2.0 significó el fin de las barreras de acceso a la comunicación a gran escala, lo que fue potenciado por las dinámicas introducidas por las redes sociales. El enorme impacto de esta revolución sólo fue posible porque la informática de consumo se volvió económicamente accesible, y sobre todo las plataformas móviles, que se convirtieron en agentes omnipresentes en el día a día de las sociedades más desarrolladas. No obstante, sería reduccionista circunscribir este cambio a la democratización del acceso a la tecnología. La convergencia, como explica Jenkins (2008, p. 3), sucede en el cerebro de los usuarios y no de sus aparatos. Hablamos, pues, de una sociedad que hoy está permanentemente conectada y que construye y hace circular el conocimiento de forma diferente. Hoy cualquiera puede producir (y distribuir) información falsa (Southwell; Thorson; Sheble, 2018; Jenkins, 2008), como consecuencia del nuevo paradigma de la comunicación que marca el fin del antiguo monopolio en el que los medios de comunicación vivieron durante más de un siglo, de modo que ahora vivimos, en palabras de Castells, en una sociedad de "autocomunicación de masas" (2015, p. 28). Esto significa que, tal y como indican Allcott y Gentzkow (2017), un individuo sin formación específica en la construcción de información o ni siquiera cierta reputación puede superar, en muchos casos, el número de lectores de empresas de comunicación tan influyentes como CNN, Fox News, The New York Times.

Jenkins, Ford y Green describen la complejidad de los flujos de comunicación que resulta de este cambio como

"Un modelo híbrido de circulación emergente, donde una combinación de fuerzas de arriba hacia abajo y de abajo hacia arriba determinan cómo se comparte el material a través y entre las culturas de una manera mucho más participativa (y más desordenada)" (Jenkins; Ford; Green, 2013, p. 1).

En este contexto, los grandes actores han dejado de controlar exclusivamente los flujos de circulación de los contenidos, y la divulgación individual ha conseguido una enorme relevancia. Jenkins, Ford y Green utilizan la expresión spreadability (capacidad de propagación, en castellano):

"La capacidad de propagación se refiere al potencial, tanto técnico como cultural, para que las audiencias compartan contenido para sus propios fines" (Jenkins; Ford; Green, 2013, p. 3).

Con la abolición de los obstáculos a la producción de contenidos por parte de los usuarios, y la consecuente diversificación de los intervinientes, el origen de las historias no sólo pasó a ser diverso, sino también difuso. Chen, Conroy y Rubin (2015) alertan de que en este contexto se difuminan las fronteras entre la producción de noticias y la creación y divulgación de información, pues son cada vez menos claras en los medios de comunicación online y en las redes sociales. Existe un mestizaje de géneros, cuyos límites el público ha dejado de comprender en algunos casos. Hirst habla incluso de la aparición del llamado user-generated El peligro está en la limitación del contacto con el otro y con la diferencia news-like content (2011, p. 110).

Otro aspecto que no toda la gente entiende perfectamente es el mecanismo que determina la información a la que libremente accede. En su libro de 1995, Ser digital, Negroponte anticipaba las virtudes del Daily me, un periódico hecho 
a medida de sus lectores. La personalización de la experiencia ha formado parte de la evolución de internet $y$, hasta que se empezó a discutir el fin de la serendipidad (Pariser, 2011), nadie parecía cuestionar sus virtudes. Sin embargo, en los últimos años esta cuestión ha empezado a abordarse desde otro prisma. Se habla mucho hoy del peligro de los filtros burbuja, como los denomina

Pariser (2011), que resultan del cambio en la forma en la que el usuario encuentra información "nueva", seleccionada por un algoritmo de un motor de búsqueda de una red social, que tiene en cuenta su historial y sus preferencias, y las de sus amigos. El peligro está en la limitación del contacto con el otro y con la diferencia en un mundo en el que la polarización se ha hecho más visible en el terreno de la política (Pool; Rosenthal, 1984), de la ciencia (Lewandowsky; Gignac; Oberauer, 2013) y, de modo general, de la propia visión de un mundo cada vez más maniqueísta (Hetherington; Weiler, 2009). Esta cuestión, a veces también denominada "cámara de eco", tiene como resultado una exposición selectiva (Del-Vicario et al., 2016, p. 554). Como explica Silverman (2016, p. 52), la exposición a un pensamiento concordante refuerza la convicción existente y la identidad del grupo. Precisamente es lo que muestra el estudio de Guess, Nyhan y Reifler, al explicar que habían sido las personas que apoyaron a Trump las que más sitios web falsos habían visitado, cuya orientación era, mayoritariamente, a favor de Trump (2018). Y aunque estudios como el de Flaxman, Goel y Rao señalen que el efecto de estos procesos no sea quizá tan profundo como se ha temido, queda clara la forma en que las redes sociales y los contenidos encontrados a través de buscadores confirman la segregación ideológica, y cómo los hábitos online tienden a confirmar los hábitos de lectura en la realidad (Flaxman; Goel; Rao, 2016).

Relacionada con la polarización, surge en este contexto otra dimensión que Trump trajo al primer plano con sus alternative facts. Es lo que Mihailidis y Viotty (2017) designan como relativismo ante el hecho. La sociedad parece cuestionar la existencia de hechos o verdades, como si cada afirmación, incluso corroborada por la ciencia o experiencia, pudiera ser contrapuesta por otras en sentido contrario con igual validez, independientemente de que en su origen existiera una motivación manipuladora:

“Hechos que ya no sirven para unificar sino que refuerzan cada vez más las ideologías partidistas y refutan los puntos de vista opuestos" (Mihailidis; Viotty, 2017, p. 448).

Pero el trabajo de Mihailidis y Viotty (2017) nos lleva aún más lejos. Cuando el usuario encuentra información que refuerza su punto de vista, ¿qué necesidad tiene de buscar más? ¿De qué le sirve evaluar la veracidad de un mensaje si no es eso lo que busca en primera instancia? En efecto, es posible que la verdad no siempre sea el principal criterio para compartir información, tal como explican Chen et al. (2015). Por eso, la alfabetización mediática e informacional debe ir más allá de la identificación de la falsedad.

\section{5. ¿Está la respuesta en la alfabetización mediática e informacional?}

Ante la infoxicación y la desinformación existentes, la apuesta por la alfabetización como parte de una respuesta multifacética - holística, como defiende Guy Berger, director de la División de la Libertad de Expresión y el Desarrollo de los Medios de Comunicación de la Unesco- a las fake news cuenta con un gran consenso. El desarrollo de la alfabetización mediática, según Mihailidis y Viotty (2017), ha permitido señalar este problema y fomentar la participación cívica de los ciudadanos, que ahora intervienen de manera directa en la circulación de la información. La alfabetización en el siglo XXI pasa, pues, por proporcionar a los usuarios las herramientas que les permitan lidiar con estas cuestiones y sacar provecho de las tecnologías en cuanto instrumentos de empoderamiento, conocimiento e integración. Es el "nuevo humanismo" que defiende la Unesco desde hace algunos años (Pérez-Tornero; Varis, 2010). Una visión global, como explican Pérez-Tornero et al.:

"porque sin esta perspectiva, podemos correr el riesgo de asumir únicamente una visión instrumental, cuando una de las necesidades actuales precisamente es incrementar el compromiso con los valores universales, los derechos humanos, y la democracia" (Pérez-Tornero et al., 2018, p. 229).

Autores como Aguaded y Romero-Rodríguez (2015; 2018), o Romero-Rodríguez, Casas-Moreno y Caldeiro-Pedreira (2018) coinciden en la importancia de las competencias mediáticas para lidiar con las particularidades del actual ecosistema informativo. De hecho, tal como explican estos autores, el problema no se limita exclusivamente a las fake news. La infoxicación se caracteriza por:

- prevalencia de contenidos de infoentretenimiento pensados para conseguir clics y no para informar;

- explotación de temas altamente sensacionalistas y atractivos;

- falta de preocupaciones deontológicas y ausencia de profundidad. Es necesario que el individuo esté preparado para lidiar con esta complejidad, y no sólo con la falsedad (Romero-Rodríguez; Casas-Moreno; Caldeiro-Pedreira, 2018, p. 75-76). 
Sin embargo, ésta es una de las cuestiones centrales:

“¿Cómo saber qué es verdad en la era de la sobrecarga de información?"

La pregunta fue formulada por Kovach y Rosenstiel (2010) antes incluso de la actual ola de noticias falsas, pero sigue más presente que nunca en los programas de alfabetización mediática. Aquí destaca una de las acciones más importantes de los últimos años: el fact checking (Lotero-Echeverri; Romero-Rodríguez; Pérez-Rodríguez, 2018, p. 313).

Sin embargo el papel de la alfabetización está lejos de centrarse en la simple identificación de noticias falsas. Cuando pensamos en las implicaciones de la polarización ideológica de la llamada era de la posverdad, es imposible no sentir inquietud ante la pregunta formulada por Mihailidis y Viotty:

"Si encontrar la verdad no es una prioridad tan importante como encontrar información personalmente relevante, ¿qué tiene de bueno saber cómo criticar un mensaje en primer lugar?” (Mihailidis; Viotty, 2017, p. 450).

Efectivamente, al ciudadano no le basta con identificar la falsedad: es necesario que también reconozca la virtud de lo contradictorio, del contacto con el otro.

Romero-Rodríguez, Valle-Razo y Torres-Toukoumidis (2018) defienden que el consumidor de información no está globalmente preparado para hacer frente a la desinformación. Para definir esa realidad Romero-Rodríguez et al. crearon el término "analfanauta", que designa a

"un individuo que tiene acceso funcional a las cuartas pantallas, a internet y sus plataformas, pero que carece de suficientes competencias mediáticas e informacionales para hacer frente a la ingente cantidad de información, pseudoinformación y desinformación online, por lo que su hábito de prosumo y filtrado de contenido no le proporciona la capacidad de comprensión de las realidades de su contexto" (Romero-Rodríguez et al., 2016, p. 13).

El habitante del ecosistema informativo del siglo XXI es un individuo enterrado en información y con tendencia al multitasking que sabe acceder y utilizar las plataformas móviles y las redes sociales, en donde busca y consume información (lo que los autores llaman "ocio informativo"), y que comparte contenidos de manera impulsiva y sin contrastar (Romero-Rodríguez et al., 2016, p. 22).

La cuestión, tal como explican estos autores es que no resulta fácil presentar un plan de acción para dirigirse a este público, ya que el riesgo de obsolescencia es muy elevado (Romero-Rodríguez et al., 2016, p. 13).

Aguaded y Romero-Rodríguez (2015) sugieren una respuesta, una "infodieta" que introduzca un equilibrio. Creemos que estos principios de equilibrio e interdependencia resultan vitales para fomentar la capacidad de respuesta de la alfabetización a los problemas que se nos plantean. Además, los trabajos de Balmas (2012) y Nielsen y Graves (2017) defienden precisamente esta perspectiva al demostrar que el consumo de fake news no tiene lugar dentro de una burbuja. El fomento del consumo de otros contenidos puede resultar determinante en la manera de hacer frente a las noticias falsas (Balmas, 2012). O, dicho de otra manera,

"Lo que piensas que son noticias falsas depende de lo que piensas de las noticias en general" (Nielsen; Graves; 2017, p. 7).

\section{Percepción de las noticias falsas en estudiantes de enseñanza superior en Portugal ¿Por qué estudiamos a los jóvenes adultos?}

Hace ya unos años que se habla de la disminución del interés de los jóvenes por las noticias de los medios de comunicación convencionales (Costera-Meijer, 2007). En la actualidad los jóvenes se informan principalmente online: en webs y en redes sociales (Catalina-García; García-Jiménez; Montes-Vozmediano, 2015; Shearer, 2018).

Sabemos que los jóvenes no son, probablemente, los mayores transmisores de noticias falsas, tal como explican Guess, Nagler y Tucker (2019). Pero también sabemos que forman el grupo más expuesto, ya que utilizan las redes con más frecuencia (Children's Commissioner, 2017; Anderson; Jiang, 2018; Smith; Anderson, 2018) y que es ahí donde reside su contacto con la práctica totalidad de la información que consumen (Media Insight Project, 2015). Asimismo, el aumento de las plataformas online como fuente de información es muy evidente, y contrasta con el estancamiento y disminución de los medios de comunicación tradicionales (Bialik; Matsa, 2017). Es aquí donde hemos de contrastar la forma en la que los jóvenes adultos se enfrentan a esas noticias falsas. Además, esta es una preocupación que no es novedosa y que tiene su génesis en la forma en la que algunos autores (Prensky, 2001; Tapscott, 1998) atribuyeron a los jóvenes cualidades generacionales homogéneas que resultaban de su exposición permanente a la tecnología ${ }^{7}$. Hoy sabemos que no es así, que la exposición no determina por sí sola el tipo de uso, y en ese campo es donde la alfabetización digital y mediática ha actuado. De hecho, a pesar de que la presencia online de los jóvenes ha pasado a ocupar espacio en los currículos y las oportunidades de formación se han ampliado, datos como los del National Literacy Trust indican que los niños y los jóvenes no están completamente preparados para lidiar con las noticias falsas en internet (National Literacy Trust, 2017). Hacia ahí se encaminaban los datos de Hargittai et al. (2010), secundados por Wineburg y McGrew (2016) y McGrew et al. (2017), que consideran que los jóvenes adultos no están bien preparados para este desafío. Es lo que demuestra el estudio de Head et al. (2018) que destaca la falta de confianza de los jóvenes universitarios a la hora de hacer frente a este problema. Otro estudio realizado también entre estudiantes de enseñanza superior demuestra que la 
mayor parte de ellos, a pesar del elevado grado de escolaridad, comparten misinformation (Chen et al., 2015). Por este motivo, los autores subrayan la importancia de que la alfabetización mediática e informacional se dirija a las motivaciones sociales que se encuentran en la base del acto de compartir.

\section{Objetivos y metodologías}

Se pretende iniciar una reflexión sobre la percepción que los jóvenes y los jóvenes adultos, estudiantes de enseñanza superior en Portugal, tienen acerca de su contacto con las noticias falsas. En este sentido, hemos definido las siguientes cuestiones de investigación:

¿Cuentan los jóvenes adultos, estudiantes de enseñanza superior, con una visión clara de qué son las noticias falsas, también conocidas como fake news?

¿Qué reacciones caracterizan su contacto con las noticias falsas?

Este es un estudio de naturaleza exploratoria y descriptiva que tiene por objetivo recopilar datos que permitan caracterizar la percepción y la actitud de los estudiantes de enseñanza superior en Portugal ante las fake news. Los criterios definidos para participar en este estudio son:

- ser estudiante de enseñanza superior;

- estar matriculado en cualquier ciclo formativo, con independencia del área de estudio, sistema de enseñanza o ubicación geográfica;

- tener una edad comprendida entre los 17 y los 25 años.

La muestra se ha recogido recurriendo a una metodología no probabilística y por conveniencia. El cuestionario, presentado en una plataforma online, fue divulgado mediante correo electrónico por docentes de enseñanza superior de diferentes disciplinas científicas en diez instituciones portuguesas, quienes los hicieron llegar a los estudiantes durante los meses de abril y mayo de 2018. Las respuestas al cuestionario se recogieron online y se procesaron en una hoja de cálculo. Se trata de un estudio de naturaleza cuantitativa.

\subsection{Cuestionario}

La redacción del cuestionario, que consta de un total de 22 preguntas, se basa en la bibliografía sobre las fake news y la desinformación, y presenta una estructura más general e introductoria al principio, para pasar a continuación a centrarse en las fake news.

Después de presentar un cuestionario piloto a cinco personas, se evaluó la inteligibilidad de las preguntas y se introdujeron los ajustes pertinentes. La estructura del cuestionario incluye la caracterización del participante (área y nivel de estudios, sexo y edad). En una primera sección se presentan preguntas cerradas y de selección múltiple que permiten recopilar información sobre la frecuencia y los hábitos de consumo de información y de uso de las redes sociales. El resto del cuestionario permite recopilar información sobre el contacto, el conocimiento y las actitudes ante las fake news, y sobre la importancia que se atribuye a esta expresión. Mediante una pregunta de selección múltiple, se pretendió recopilar información sobre el significado que los participantes atribuyen a la expresión fake news. Entre las posibles respuestas (ver resultados) se incluyeron referencias a otras manifestaciones propias de la desinformación. También se formularon preguntas sobre la contrastación de noticias falsas, las características de este tipo de contenidos y su influencia en el comportamiento online de los participantes. Para evaluar el recuerdo que dejan las fake news, se formuló una pregunta abierta en la que se pedía que describiesen la última noticia falsa identificada como tal. También se formuló una pregunta de selección múltiple sobre el comportamiento adoptado cuando se detecta una noticia falsa, para permitir una referencia explícita a las webs de fact checking.

\subsection{Caracterización de la muestra}

La muestra está constituida por 602 individuos (23,4\% hombres y 76,6\% mujeres) con edades comprendidas entre los 17 y los 20 años (33,9\%) y los 21 y 25 años $(66,1 \%)$, estudiantes de enseñanza superior en Portugal.

Por lo que respecta a su formación, se trata de estudiantes de grado (67,7\%), máster (30,5\%), doctorado (1\%), ciclos formativos de grado superior $(0,2 \%)$ y cursos que no conceden título de grado $(0,7 \%)$, en las áreas de las ciencias sociales $(47,7 \%)$, humanidades $(27 \%)$, ciencias de la salud $(6,4 \%)$, ciencias y tecnologías $(13,3 \%)$, artes $(5,6 \%)$ y deporte $(0,2 \%)$.

\section{Resultados}

\subsection{Uso de redes sociales}

Se trata mayoritariamente de individuos que usan habitualmente las redes sociales $(97,5 \%)$, a las cuales dedican diariamente entre una y tres horas $(35,2 \%)$, entre tres y cinco horas $(34,4 \%)$, más de cinco horas $(19,1 \%)$, menos de una hora $(9,3 \%)$; y otros usuarios no diarios $(1,3 \%)$ y no usuarios $(0,7 \%)$.

Las redes que usan habitualmente son Instagram (el 71\% de las personas que respondieron), Facebook (68\%) y YouTube (68\%). Únicamente el $16 \%$ de los que respondieron indicó Twitter. 
Tabla 1. Uso de redes sociales

\begin{tabular}{|c|c|c|c|c|c|c|}
\hline Instagram & Facebook & YouTube & Twitter & Snapchat & Pinterest & Otras \\
\hline $71 \%$ & $68 \%$ & $68 \%$ & $16 \%$ & $4 \%$ & $12 \%$ & $9 \%$ \\
\hline
\end{tabular}

\subsection{Consumo de noticias}

Mayoritariamente, los encuestados respondieron que se consideran interesados por la actualidad informativa (97,3\%).

Observando sus preferencias aisladamente, la mayor parte de los participantes prefiere consultar noticias online (en webs el 75\%, y en las redes sociales el 63\%), seguido por la televisión (58\%), prensa (36\%) y radio (16\%).

Combinando sus ajustes con los medios anteriormente indicados, se identifican los perfiles más importantes:

- consumidores de noticias en webs y redes sociales $(17,4 \%)$;

- consumidores de noticias en webs, redes sociales y televisión (15,5\%);

- consumidores de noticias en webs, redes sociales, televisión y periódicos (11,2\%).

Con relación a su actitud ante las noticias online, la mayoría de las personas que respondieron (73,9\%) afirman que suelen leer sobre todo los titulares, aunque a veces también lean algunas noticias cuando el tema les interesa. Los porcentajes de personas que afirman leer todo o casi todo son más bajos $(5,3 \%)$, incluso cuando el tema no es inmediatamente de su interés $(19,4 \%)$ o que sólo leen los titulares (1,3\%).

\subsection{Percepción y actitudes con respecto a las noticias falsas}

Las noticias falsas son una realidad de la que el 98,3\% de los participantes ya había oído hablar.

La gran mayoría considera que las noticias falsas son un fenómeno preocupante $(91,8 \%)$, mientras que los restantes se muestran indiferentes (5,3\%) o no preocupados (2,8\%). A pesar de ello, el $99,3 \%$ de los encuestados afirma que las noticias falsas pueden influir en la formación de la opinión de las personas.

Un poco más de la mitad (56\%) de la muestra afirma haber sido engañados por noticias falsas, lo que sucedió en el último año el $73,1 \%$ de las veces; hace dos o tres años (20,7\%); y hace más de tres años $(6,3 \%)$.

Cuando se les preguntó por la última noticia falsa con la que se habían encontrado, el 49\% de los encuestados respondieron que se trataba de una noticia compartida por amigos en redes sociales, el 32\% afirmó que había sido compartida directamente por medios de comunicación en las redes sociales, y el 11\% en la web de un medio de comunicación. Sólo el $7 \%$ indicó que se encontraron con una noticia falsa fuera de internet.

\section{4. ¿Qué es una noticia falsa?}

Cuando se les formuló una pregunta cerrada de respuesta múltiple sobre qué puede considerarse una noticia falsa:

- el 97\% respondió: "noticia falsa deliberadamente disfrazada de noticia verdadera";

- el 73\% señala: "información falsa inadvertidamente compartida por ciudadanos en internet" y "un titular que después no se corresponde con exactitud a lo que se trata en la noticia (clickbait)"

También se identificaron como noticias falsas:

- "noticia con enfoque sensacionalista" (38\%);

- "noticia con tratamiento superficial del asunto" (27\%);

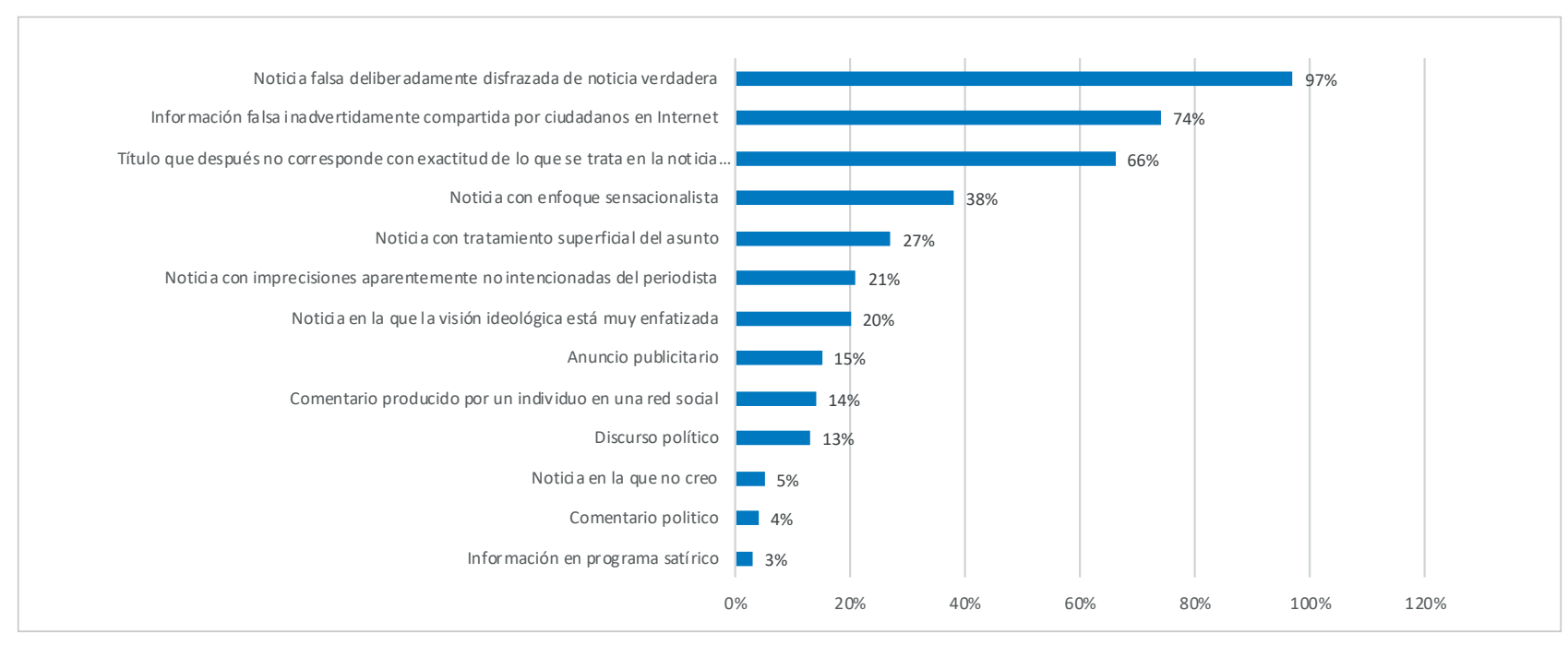

Gráfico 1. ¿Qué puede considerarse "noticia falsa"? 
- "noticia con imprecisiones aparentemente no intencionadas del periodista" (21\%);

- "noticia en la que la visión ideológica está muy enfatizada" (20\%).

Otras opciones, como "comentario realizado por un individuo en una red social", "anuncio publicitario", "discurso político", "información en programa satírico", "comentario político" y "noticia en la que no creo", fueron menos frecuentes.

Con relación a la última noticia falsa con la que se encontraron, las características más destacadas por los encuestados fueron el hecho de ser algo sorprendente (69\% de los que contestaron a esta pregunta) y verosímil (45\%). Opciones como "violenta" fueron escogidas por el $25 \%$ de los encuestados, "contraria a sus puntos de vista" (22\%) y "coincidente con sus convicciones" (21\%). Las restantes opciones carecen de relevancia.

La recogida de datos de la percepción de los individuos sobre las noticias falsas permite cruzar un análisis de naturaleza cualitativa con la metodología cuantitativa escogida para este estudio. Ante la posibilidad de respuesta abierta para identificar una (la última) noticia falsa por la que hayan sido engañados, se registraron 152 respuestas. Al agrupar las respuestas en categorías, hemos encontrado las "celebridades" ( $n=21)$ como la temática más importante, dentro de la cual destaca la "muerte" ( $n=7)$. Las respuestas más explícitas indican los nombres de Sylvester Stallone o Jackie Chan. En efecto, son dos ejemplos documentados y desmentidos en una de las webs más antiguas de comprobación de hechos: Snopes. Sin embargo, en esta categoría surgen otras referencias que no se encuadran en la definición de noticia falsa que hemos adoptado. Es el caso de la referencia a "Daniela Ruah y Catarina Furtado a besos" 8 , una historia incluida en una producción de moda real relatada en varios medios portugueses. O también del error inicial y la corrección posterior del periodista:

"muerte de Avici en la que inicialmente había fallecido por exceso de alcohol, pero después había resultado ser un suicidio. La primera información no se da con un $100 \%$ de seguridad".

El mundo del deporte, sobre todo el fútbol, también se menciona. Una de las respuestas refleja bien las equivocaciones acerca de la diferencia entre el sensacionalismo y la falsedad:

"No me acuerdo, pero tuvo que ver con un escándalo del Sporting y de Bruno de Carvalho. Fue todo muy exagerado, no se correspondía con la verdad de lo que estaba pasando, y provocó una situación sensacionalista".

También se hace reiterada referencia a la caída de un avión durante la lucha contra los incendios en Portugal ( $n=4)$, una historia posteriormente desmentida que tuvo su origen en una explosión mal identificada y divulgada por los periodistas.

El presidente Donald Trump ( $n=6)$ surge también como una referencia, aunque sin detalles que permitan identificar los episodios. También para la misma pregunta, a pesar de haber encuestados que afirman explícitamente que no se acuerdan de la (última) noticia falsa $(n=15)$, la ausencia de respuesta a esta pregunta es significativa. Con relación al $56 \%$ de la muestra que indica haber sido engañada por una noticia falsa, sólo el $36 \%(n=152)$ ha respondido a esta pregunta.

Ante la pregunta sobre qué actitud tomar ante una noticia que causa duda, las opciones cerradas de respuesta múltiple fueron las más escogidas, a pesar de existir la posibilidad de responder de modo abierto. En esta última, solamente un encuestado indica una referencia explícita a la consulta de una web de verificación de hechos (y corresponde al 0,2\% de las personas que respondieron a esta pregunta), una opción que no estaba disponible en respuesta múltiple cerrada. Otro encuestado afirmó "preguntar a otra persona si creía en la veracidad" (0,2\%) y otro refirió que preguntaría en las redes sociales $(0,2 \%)$. Cinco individuos presentaron respuestas que apuntan hacia la consulta de diversas fuentes y el cruce de datos, y otros cinco corroboran la tendencia comprobada en las preguntas de respuesta múltiple, al indicar la consulta en organismos que ellos consideran de fiar. Precisamente cuando se les formula una pregunta cerrada sobre qué actitud tomarían si se enfrentaran a noticias que les plantearan dudas, la mayoría de los encuestados respondió que recurriría a internet para consultar medios que consideran de fiar (el 64\% de la muestra). Existe también un importante porcentaje que afirma que recurriría a los resultados del buscador (15\%) para confirmar sus dudas. Sólo el 10\% afirma que buscaría confirmación en la televisión, y el 6\% en la prensa. Los restantes resultados carecen de importancia.

Con relación a la percepción de fraude suscitada por la última noticia falsa que vieron, el 59,6\% de la muestra afirma haber tenido dudas y, debido a ello, buscaron aclaraciones; el 22,5\% afirma haberse encontrado casualmente con información contraria, y el 17,8\% que alguien los alertó activamente.

Las cuestiones finales de la encuesta querían contrastar si el contacto y el conocimiento actual de las noticias falsas han implicado algún cambio en el comportamiento de los encuestados, hecho que se confirma por parte de un $82,3 \%$ de los individuos. Ante la posibilidad de respuesta múltiple, el 94,3\% de los individuos escogió la expresión "Soy más desconfiado con relación a lo que leo en las redes sociales", el 91,9\% de los encuestados escogió "He pasado a buscar más información sobre el tema en otros sitios que considero de fiar" $y$, además, se registraron los siguientes porcentajes de elección: "Veo la procedencia de la noticia" (88,5\%), "Creo cada vez menos en lo que veo en internet" $(71,7 \%)$ y "Soy más desconfiado con relación a las noticias, independientemente del medio" $(79,4 \%)$.

Los jóvenes identifican muchos de los males del actual ecosistema informativo, pero no son capaces de catalogarlos de manera totalmente correcta 


\section{Discusión}

En una muestra compuesta por individuos con edades comprendidas entre los 17 y los 25 años, todos ellos estudiantes de enseñanza superior en Portugal, encontramos una evidente preferencia por el consumo de información online, y una menor relevancia de los llamados medios tradicionales. Destacamos la menor importancia de la televisión, que, en otros estudios como el de ERC (2016) está más presente, lo que puede deberse a un cambio en los usos sucedido en los dos años que separan a ambos estudios, o a las características específicas de la composición de esta muestra, y más concretamente a la edad o incluso a la posibilidad de que muchos de los encuestados residan temporalmente fuera de casa. Obsérvese, no obstante, que los datos recientes (Jiang, 2018) relativos a América del Norte pueden ayudar a ver esta diferencia como una posible tendencia, al mostrar que el número de personas que no dejarían la televisión es cada vez menor, y sólo el $16 \%$ de los jóvenes se encontraba en esa situación.

La muestra de jóvenes adultos es claramente consciente de la existencia de las noticias falsas, aunque las fronteras de su definición no queden claras para todos. Aunque se definen con relativa claridad en el ámbito académico, las fake news no son bien reconocidas ni delimitadas por la muestra. Las noticias satíricas, por ejemplo, prácticamente no se consideran como pertenecientes a esta categoría.

Por otra parte, aunque de forma minoritaria en la muestra, dentro de la categoría de noticias falsas acaban entrando criterios como la superficialidad o el sensacionalismo en el tratamiento periodístico, características que, efectivamente, se asocian a la desinformación y a la infoxicación. El propio error involuntario, sobre todo el resultante de la presión derivada del poco tiempo que existe en el periodismo contemporáneo, acaba por catalogarse como noticia falsa. En este sentido, observamos que estos jóvenes identifican muchos de los males del actual ecosistema informativo, pero no son capaces de catalogarlos de manera totalmente correcta. Aunque no sea la única lectura posible, consideramos que esta percepción coincide por completo con la idea de que las fake news están lejos de constituir el mayor de los problemas. El panorama es mucho más complejo.

\section{Las fake news están lejos de constituir el mayor de los problemas. El panorama es mucho más complejo}

A pesar de saber de la tendencia a no contestar preguntas abiertas (Reja et al., 2003), la falta de respuestas acerca de la última noticia falsa vista por los individuos de la muestra nos lleva a plantear la hipótesis de que, aunque este fenómeno sea reciente, no deja un recuerdo muy profundo, tal vez debido a la cantidad de información con la que estos jóvenes y jóvenes adultos se encuentran diariamente. ¿Estamos ante lo que James Gleick (2011, p. 25) denomina "information fatigue, anxiety and glut" (fatiga de la información, anxiedad y exceso)? Sin duda, la cantidad de información con la que el individuo se encuentra a diario es abrumadora y le plantea múltiples desafíos. Pero, precisamente por ello, ¿ pasará ésta por la mayoría de nosotros sin dejar rastro? En materia de desinfoxicación, ¿seremos demasiado soberbios para que algo nos deje una marca?

De todos modos, en este contexto, el viejo debate de hace un siglo entre Dewey y Lippman a propósito de la democracia y del papel de la información en la formación de la opinión pública y de la participación de ésta en la sociedad se mantiene vigente. Con una pequeña, pero sustancial, diferencia: la manipulación y la desinformación han dejado de ser, como hemos visto, un monopolio de los medios de comunicación.

Los resultados obtenidos nos muestran un grupo en el que los individuos se consideran mayoritariamente proactivos y decididos a buscar información ante la duda. No obstante, entendemos que estos resultados deben considerarse con prudencia:

- los resultados que no reflejen esa proactividad también son relevantes;

- será prudente tener en cuenta un posible sesgo causado por lo que socialmente se espera en las respuestas a encuestas.

Dos son los aspectos que refuerzan nuestra lectura:

- la referencia residual a la verificación de los hechos en las respuestas;

- estudios como el de Hargittai et al. (2010), que muestran que las respuestas a las encuestas no siempre coinciden con la práctica del uso online.

Nos parece que esa prudencia se debe tener, igualmente, en la lectura de los datos referentes a las percepciones personales de cambio de actitud en la actualidad. No obstante, los resultados muestran un conjunto de jóvenes y jóvenes adultos que consideran que su comportamiento ha cambiado, y que hoy existe una mayor desconfianza, sobre todo con respecto a la información online.
La cantidad de información con la que el individuo se encuentra a diario es abrumadora y le plantea múltiples desafíos. Pero, precisamente por ello, ¿pasará ésta por la mayoría de nosotros sin dejar rastro?

Tal como Guess, Nyhan y Reifler (2018, p. 2) mostraron, las redes sociales son el mecanismo que más facilita la circulación de noticias falsas, lo que se confirma gracias a esta muestra. 
La importancia de la credibilidad es uno de los factores que más destaca en el análisis de los datos. Más de la mitad de los individuos de la muestra hacen referencia a la consulta de noticias en webs que consideran de fiar, ya sea como un método de comprobación en caso de duda, ya sea como consecuencia de la creciente desinformación. Esta lectura nos plantea cuestiones que resultan, primordialmente, de la forma en que se evalúa dicha credibilidad, dado que existe una asociación entre el hábito y la confianza. Es normal que el lector confíe en lo que habitualmente lee. Hoy, como explica Silverman (2016), muchas informaciones falsas sólo se vuelven realmente ubicuas cuando los medios les dan crédito y las distribuyen sin cuestionarlas ni confirmarlas. Fue lo que sucedió en Timisoara, entre tantos otros casos.

La fiabilidad de la fuente es un factor primordial para que un rumor tenga crédito (Silverman, 2016). Obsérvese el caso de los Estados Unidos, donde únicamente el 17\% de los ciudadanos consideran que los medios de comunicación son muy exactos. Sin embargo, esta cifra se duplica cuando se refiere a los medios habitualmente consumidos por encuestados: las personas confían en sus fuentes habituales (Media Insight Project, 2017). Fue esto lo que, durante décadas, convirtió a los medios de comunicación en los principales actores de la manipulación: la gente espera poder confiar en ellos. Y es esto lo que sucede en la actualidad, cuando el usuario recibe un mensaje compartido a través de una red social por uno de sus contactos. Romero-Rodríguez, Valle-Razo y Torres-Toukoumidis (2018, p. 266) lo llaman "autoanuencia".

La lectura que hacemos de estos resultados apunta a la importancia de la alfabetización mediática e informacional. Más concretamente, los datos sugieren la importancia del refuerzo de la concienciación de la credibilidad, de los comportamientos de la comprobación de la información online y acerca de las propias dinámicas actuales de la circulación de información. Considerando que la familiaridad con el uso de un aparato se puede confundir muchas veces con la competencia mediática y, por otra parte, que pueden existir otros factores - además del interés por la verdad-que llevan a compartir, nos parece importante que el abordaje de la alfabetización mediática e informacional se lleve a cabo desde diferentes puntos de vista. No se trata sólo de hacer llegar al público el "skeptical knowing" (Kovach; Rosenstiel, 2010) de los periodistas y fomentar el fact Más que actuar para protegerse a sí mismo, el individuo debe tener conciencia social y ética

checking. Se trata, sobre todo, de concienciar sobre el hecho de que las acciones de uno influyen en la vida de todos, tal como sucede en el caso del medio ambiente. Y así, más que actuar para protegerse a sí mismo, el individuo debe tener conciencia social y ética.

\section{Limitaciones del estudio}

Este estudio presenta las limitaciones inherentes a un estudio exploratorio con muestra recogida por conveniencia en la que existe un predominio de individuos con formación en ciencias sociales y humanidades, así como una clara superioridad de respuestas del sexo femenino. Así pues, no nos es posible afirmar que los resultados serían los mismos con una composición diferente de la muestra. Del mismo modo, la muestra no es representativa de los jóvenes y jóvenes adultos portugueses que frecuentan la universidad. E igualmente, su dimensión supuso una limitación de la profundidad estadística, sobre todo en lo relativo al cruce de variables. La composición de la muestra y un diseño que permita una mayor profundidad estadística son, pues, aspectos importantes a tener en cuenta de cara al futuro de esta investigación.

\section{Notas}

1. Aunque en general las noticias falsas se consideren un fenómeno perjudicial, una de sus caras más visibles surgió en televisión durante el siglo XX, con gran complacencia por parte del público. Las noticias falsas en programas satíricos de televisión son un género que ha ganado una enorme proyección, sobre todo con el Daily show (1996-presente) y Colbert report (2005-2014) (Tally, 2011; Love, 2007). Tandoc, Lim y Ling (2017) las clasificaron en función de si tenían una baja intención de engañar. Al contrario de las noticias falsas en las que nos centramos en este artículo, algunos vieron las noticias satíricas como un medio capaz de lidiar con la manipulación de forma más eficaz que el periodismo:

"dado el extraordinario nivel de distorsiones, mentiras y giros (...) tal vez la noción posmoderna de que lo "falso" es más real que lo "real" no es una noción tan inquietante cuando se trata de ciudadanos que buscan la verdad en la comunicacion política contemporánea en la televisión" (Jones, 2007, p. 130).

2. Texto original en:

https://elpais.com/diario/1989/12/29/internacional/630889212_850215.html

3. Se trató de un conjunto de historias sobre la vida en la Luna publicadas en 1835 por el New York Sun, un periódico dirigido por primera vez a la clase obrera cuyo éxito fue catapultado, precisamente, por estas historias (Thornton, 2000; Love, 2007; Allcott; Gentzkow, 2017).

4. En el original,

"noticias que son intencionalmente y verificadamente falsas, y podrían engañar a los lectores (...) Nuestra definición excluye a varios primos cercanos de las noticias falsas: 1) errores de información no intencionales, (...) 2) rumores que no se originan en una noticia en particular; 3) teorías de conspiración, (...) 4) sátiras que es poco probable que se malinterpreten como hechos; 5) declaraciones falsas de los políticos; y 6) informes que son sesgados o engañosos pero no absolutamente falsos" (Allcott; Gentzkow, 2017, p. 213-214). 
5. Esta clasificación ayuda a explicar la potencial desinformación de las fake news. Por ejemplo, las noticias satíricas tienen un elevado grado de facticidad y una baja intención de engañar. Por el contrario, las noticias fabricadas tienen una elevada intención de engañar y una baja facticidad.

6. Los ciudadanos consideran que los medios no son libres en su actuación. Datos actuales sobre la confianza en los medios en los informes de la Comisión Europea (2017; 2017b), del Reuters Institute (Newman et al., 2017) y de Media Insight Project (2017).

7. Autores como Bennett, Maton y Kervin (2008) o Coombes (2009) refutan esta idea de la homogeneidad.

8. Dos celebridades portuguesas.

\section{Referencias}

Aguaded, Ignacio; Romero-Rodríguez, Luis M. (2015). “Mediamorfosis y desinformación en la infoesfera: Alfabetización mediática, digital e informacional ante los cambios de hábitos de consumo informativo". Education in the knowledge society, v. 16, n. 1, pp. 44-57.

http://revistas.usal.es/index.php/eks/article/view/12701

Aguaded, Ignacio; Romero-Rodríguez, Luis (eds.) (2018). Competencias mediáticas en medios digitales emergentes. Salamanca: Comunicación Social Ediciones y Publicaciones. ISBN: 9788417600037

Allcott, Hunt; Gentzkow, Matthew (2017). "Social media and fake news in the 2016 election". Journal of economic perspectives, v. 31, n. 2, pp. 211-236.

https://doi.org/10.1257/jep.31.2.211

Anderson, Monica; Jiang, Jingjing (2018). Teens, social media \& technology 2018. Pew Research Center. http://assets.pewresearch.org/wp-content/uploads/sites/14/2018/05/31102617/PI_2018.05.31_TeensTech_FINAL.pdf

Balmas, Meital (2012). "When fake news becomes real: Combined exposure to multiple news sources and political attitudes of inefficacy, alienation, and cynicism". Communication research, v. 20, n. 10, pp. 1-25.

https://doi.org/10.1177/0093650212453600

Benito-Ruiz, Elena (2009). “Infoxication 2.0”. In: Thomas, Michael (ed.). Handbook of research on web 2.0 and second language learning. Hershey: IGI Global, pp. 60-79. ISBN: 9781605661902

Bennett, Sue; Maton, Karl; Kervin, Lisa (2008). "The 'digital natives' debate: A critical review of the evidence”. British journal of educational technology, v. 39, n. 5, pp. 775-786.

https://doi.org/10.1111/j.1467-8535.2007.00793.x

Bialik, Kristen; Matsa, Katerina-Eva (2017). "Key trends in social and digital news media". Factank. News in the numbers. Pew Research Center, October 4.

http://www.pewresearch.org/fact-tank/2017/10/04/key-trends-in-social-and-digital-news-media

Breton, Philippe (2002). A palavra manipulada. Lisboa: Editorial Caminho. ISBN: 9789722114516

Castells, Manuel (2015). Redes de indignación y esperanza. Los movimientos sociales en la era de internet. Madrid: Alianza Editorial. ISBN: 9788420609607

Catalina-García, Beatriz; García-Jiménez, Antonio; Montes-Vozmediano, Manuel (2015). “Jóvenes y consumo de noticias a través de internet y los medios sociales”. Historia y comunicación social, v. 20, n. 2, pp. 601-619.

https://doi.org/10.5209/rev_HICS.2015.v20.n2.51402

Chen, Xinran; Sin, Sei-Ching-Joanna; Theng, Yin-Leng; Lee, Chei-Sian (2015). "Why students share misinformation on social media: Motivation, gender, and study-level differences". The journal of academic librarianship, v. 41, pp. 583-592. https://doi.org/10.1016/j.acalib.2015.07.003

Chen, Yimin; Conroy, Nial J.; Rubin, Victoria L. (2015). “News in an online world: The need for an 'automatic crap detector'”. In: Proceedings of the Association for Information Science and Technology, v. 52, n. 1, pp. 1-4. https://doi.org/10.1002/pra2.2015.145052010081

Children's Commissioner (2017). Growing up digital. A report of the growing up digital taskforce.

https://www.childrenscommissioner.gov.uk/wp-content/uploads/2017/06/Growing-Up-Digital-Taskforce-ReportJanuary-2017_0.pdf

Coombes, Barbara (2009). “Gen Y: Are they really digital natives or more like digital refugees?”. Synergy, v. 7, n. 1, pp. 31-40.

Costera-Meijer, Irene (2007). "The paradox of popularity: How young people experience the news". Journalism studies, v. 8 , n. 1, pp. $96-116$.

https://doi.org/10.1080/14616700601056874 
Del-Vicario, Michela; Bessi, Alessandro; Zollo, Fabiana; Petroni, Fabio; Scala, Antonio; Caldarelli, Guido; Stanley, H. Eugene; Quattrociocchi, Walter (2016). "The spreading of misinformation online". In: Proceedings of the National Academy of Sciences, v. 113, n. 3, pp. 554-559.

https://doi.org/10.1073/pnas.1517441113

ERC (2016). As novas dinâmicas do consumo audiovisual em Portugal. Entidade Reguladora para a Comunicação Social. ISBN: 9789892065939

European Commission (2017a). Special eurobarometer 461. Designing Europe's future: Trust in institutions, globalisation, support for the euro, opinions about free trade and solidarity. Brussels: European Commission.

http://ec.europa.eu/commfrontoffice/publicopinion/index.cfm/Survey/getSurveyDetail/instruments/SPECIAL/surveyKy/2173

European Commission (2017b). Standard eurobarometer 88. Media use in the European Union. Brussels: European Commission.

http://ec.europa.eu/commfrontoffice/publicopinion/index.cfm/Survey/getSurveyDetail/instruments/STANDARD/surveyKy/2143

European Commission (2018). A multi-dimensional approach to disinformation. Report of the Independent High Level Group on Fake News and Online Disinformation. Luxembourg: Publications Office of the European Union.

https://doi.org/10.2759/739290

Flaxman, Seth; Goel, Sharad; Rao, Justin M. (2016). "Filter bubbles, echo chambers, and online news consumption". Public opinion quarterly, v. 80, n. S1, pp. 298-320.

https://doi.org/10.1093/poq/nfw006

Fuller, Jack (2010). What is happening to news: The information explosion and the crisis in journalism. Chicago: The Chicago University Press. ISBN: 9780226268989

Galdón-López, Gabriel (2001). Desinformação e os limites da informação. Lisboa: Folhas \& Letras. ISBN: 9789728800053

Gleick, James (2011). The information: A history, a theory, a flood. New York: Pantheon Books. ISBN: 9781400096237

Guess, Andrew; Nagler, Jonathan; Tucker, Joshua (2019). "Less than you think: Prevalence and predictors of fake news dissemination on Facebook". Science advances, v. 5, n. 1, eaau4586.

https://doi.org/10.1126/sciadv.aau4586

Guess, Andrew; Nyhan, Brendan; Reifler, Jason (2018). Selective exposure to misinformation: Evidence from the consumption of fake news during the 2016 U.S. presidential campaign. European Research Council.

https://www.dartmouth.edu/ nyhan/fake-news-2016.pdf

Hargittai, Eszter; Fullerton, Lindsay; Menchen-Trevino, Ericka; Thomas, Kristin-Yates (2010). "Trust online: Young adults' evaluation of web content". International journal of communication, v. 4, pp. 468-494.

https://ijoc.org/index.php/ijoc/article/view/636

Head, Alison J.; Wihbey, John; Metaxas, P. Takis; MacMillan, Margy; Cohen, Dan (2018). How students engage with news: Five takeaways for educators, journalists, and librarians. Project information literacy, October 16.

http://projectinfolit.org/news_study

Hetherington, Mark J.; Weiler, Jonathan D. (2009). Authoritarianism and polarization in American politics. Cambridge: Cambridge University Press. ISBN: 9780521711241

Hirst, Martin (ed.). News 2.0: Can journalism survive the internet?. Singapore: Allen \& Unwin, pp. 108-128. ISBN: 9781 742370576

Jenkins, Henry (2008). Convergence culture: Where old and new media collide. New York: New York University Press. ISBN: 9780814742952

https://cutt.ly/jsDdSo

Jenkins, Henry; Ford, Sam; Green, Joshua (2013). Spreadable media: Creating value and meaning in a networked culture. New York: New York University Press. ISBN: 9780814743508

Jiang, Jingjing (2018c). "Millennials stand out for their technology use, but older generations also embrace digital life". Factank. News in the numbers. Pew Research Center, May 2.

http://www.pewresearch.org/fact-tank/2018/05/02/millennials-stand-out-for-their-technology-use-but-oldergenerations-also-embrace-digital-life

Jones, Jeffrey (2007). “'Fake' news versus 'real' news as sources of political information: The daily show and postmodern political reality". In: Riegert, Kristina (ed.). Politicotainment: Television's take on the real. New York: Peter Lang Publishers, pp. 129-149. ISBN: 9780820481142

Kovach, Bill; Rosenstiel, Tom (2004). Os elementos do jornalismo. Porto: Porto Editora. ISBN: 9789720452573 
Kovach, Bill; Rosenstiel, Tom (2010). Blur: How to know what's true in the age of information overload. New York: Bloomsbury. ISBN: 9781608193011

Lewandowsky, Stephan; Gignac, Gilles E.; Oberauer, Klaus (2013). "The role of conspiracist ideation and worldviews in predicting rejection of science". Plos one, v. 10, n. 8, e0134773.

https://doi.org/10.1371/journal.pone.0075637

Lewandowsky, Stephan; Stritzke, Werner G. K.; Freund, Alexandra M.; Oberauer, Klaus; Krueger, Joachim I. (2013). "Misinformation, disinformation, and violent conflict: From Iraq and the 'war on terror' to future threats to peace". American psychologist, v. 68, n. 7, pp. 487-501.

https://doi.org/10.1037/a0034515

Lotero-Echeverri, Gabriel; Romero-Rodríguez, Luis M.; Pérez-Rodríguez, Amor (2018). "Fact-checking vs. fake news: Periodismo de confirmación como recurso de la competencia mediática contra la desinformación”. Index.comunicación, v. 8, n. 2, pp. 295-316.

http://journals.sfu.ca/indexcomunicacion/index.php/indexcomunicacion/article/view/370/400

Love, Robert (2007). "Before Jon Stewart". Columbia journalism review, v. 45, n. 6, pp. 33-37.

https://archives.cjr.org/feature/before_jon_stewart.php

McChesney, Robert; Nichols, John (2010). The death and life of American journalism: The media revolution that will begin the world again. Philadelphia: Nation Books. ISBN: 9781568586052

McGrew, Sarah; Ortega, Teresa; Breakstone, Joel; Wineburg, Sam (2017). "The challenge that's bigger than fake news: Civic reasoning in a social media environment". American educator, v. 4, n. 3, pp. 4-9.

https://www.aft.org/sites/default/files/ae_fall2017.pdf

Media Insight Project (2015). "How millennials get news: Inside the habits of America's first digital generation". American Press Institute, March 16.

https://www.americanpressinstitute.org/publications/reports/survey-research/millennials-news

Media Insight Project (2017). "'My' media versus 'the' media: Trust in news depends on which news media you mean”. American Press Institute, May 24.

https://www.americanpressinstitute.org/publications/reports/survey-research/my-media-vs-the-media/single-page

Mihailidis, Paul; Viotty, Samantha (2017). "Spreadable spectacle in digital culture: Civic expression, fake news, and the role of media literacies in 'post-fact' society". American behavioral scientist, v. 61, n. 4, pp. 441-454.

https://doi.org/10.1177/0002764217701217

National Literacy Trust (2017). Fake news and critical literacy: The final report of the Commission on Fake News and the Teaching of Critical Literacy in Schools.

https://literacytrust.org.uk/documents/1722/Fake_news_and_critical_literacy_-_final_report.pdf

Negroponte, Nicholas (1996). Ser digital. Lisboa: Editorial Caminho. ISBN: 9789722110563

Newman, Nic; Fletcher, Richard; Kalogeropoulos, Antonis; Levy, David A. L.; Nielsen, Rasmus-Kleis (2017). Reuters Institute. Digital news report 2017.

https://reutersinstitute.politics.ox.ac.uk/sites/default/files/Digital\%20News\%20Report\%202017\%20web_0.pdf

Nielsen, Rasmus-Kleis (2016). "The many crises of Western journalism: A comparative analysis of economic crises, professional crises, and crises of confidence". In: Alexander, Jeffrey; Breese, Elizabeth-Butler; Luengo, Maria (eds.). The crisis of journalism reconsidered: Democratic culture, professional codes, digital future. Cambridge: Cambridge University Press, pp. 77-97. ISBN: 9781107448513

Nielsen, Rasmus-Kleis; Graves, Lucas (2017). 'News you don't believe': Audience perspectives on fake news. Reuters Institute for the Study of Journalism report.

https://reutersinstitute.politics.ox.ac.uk/sites/default/files/2017-10/Nielsen\%26Graves_factsheet_1710v3_FINAL_download.pdf

Otte, Max (2010). El crash de la información. Los mecanismos de la desinformación cotidiana. Barcelona: Editorial Planeta. ISBN: 9788434469235

Pariser, Eli (2011). The filter bubble: What the internet is hiding from you. London: Penguin Press. ISBN: 9780241954522

Pérez-Tornero, José-Manuel; Tayie, Sally-Samy; Tejedor, Santiago; Pulido, Cristina (2018). “¿Cómo afrontar las noticias falseadas mediante la alfabetización periodística? Estado de la cuestión”. Doxa comunicación, n. 26, pp. 211-235. https://doi.org/10.31921/doxacom.n26a10

Pérez-Tornero, José-Manuel; Varis, Tapio (2010). Media literacy and new humanism. Moskow: Unesco Institute for Information Technologies in Education. ISBN: 9785905175053

https://iite.unesco.org/pics/publications/en/files/3214678.pdf 
Pool, Keith T.; Rosenthal, Howard (1984). “The polarization of American politics”. The journal of politics, v. 46, n. 4, pp. $1061-1079$. https://doi.org/10.2307/2131242

Prensky, Marc (2001). "Digital natives, digital immigrants". On the horizon, v. 9, n. 5, pp. 1-6.

https://www.marcprensky.com/writing/Prensky\%20-\%20Digital\%20Natives,\%20Digital\%20Immigrants\%20-\%20Part1.pdf

Reja, Ursa; Manfreda, Katja-Lozar; Hlebec, Valentina; Vehovar, Vasja (2003). “Open-ended vs. close-ended questions in web questionnaires". Developments in applied statistics, v. 19, n. 1, pp. 159-177.

https://www.stat-d.si/mz/mz19/reja.pdf

Ramonet, Ignacio (1990). “Le coupable silence des médias”. In: De-Selys, Gérard (org.). Médiamensonges. Bruxelles: Éditions EPO, pp. 55-62.

Romero-Rodríguez, Luis M.; Casas-Moreno, Patricia; Caldeiro-Pedreira, Mari-Carmen (2018). “Desinformación e infoxicación en las cuartas pantallas". In: Aguaded, Ignacio; Romero-Rodríguez, Luis M. Competencia mediática en medios digitales emergentes. Salamanca: Comunicación Social Ediciones y Publicaciones, pp. 73-92. ISBN: 9788417600037

http://www.romero-rodriguez.com/portfolio-items/desinformacion-e-infoxicacion-en-las-cuartas-pantallas

Romero-Rodríguez, Luis M.; Torres-Toukoumidis, Ángel; Pérez-Rodríguez, M. Amor; Aguaded, Ignacio (2016). “Analfanautas y la cuarta pantalla: ausencia de infodietas y de competencias mediáticas e informaciones en jóvenes universitarios latinoamericanos". Fonseca, journal of communication, v. 12, pp. 11-25.

https://doi.org/10.14201/fjc2016121125

Romero-Rodríguez, Luis M.; Valle-Razo, Ana; Torres-Toukoumidis, Ángel (2018). "Hacia una construcción conceptual de las fake news: Epistemologías y tipologías de las nuevas formas de desinformación". In: Pérez-Serrano, María-José; Alcolea-Díaz, Gema; Nogales-Bocio, Antonia I. Poder y medios en las sociedades del siglo XXI. Sevilla: Egregius, pp. 259273. ISBN: 9788417270698

https://cutt.ly/whDn96

Serrano, Pascual (2009). Desinformación: cómo los medios ocultan el mundo. Barcelona: Ediciones Península. ISBN: 978 8483078808

Shearer, Elisa (2018). "Social media outpaces print newspapers in the U.S. as a news source". Factank. News in the numbers. Pew Research Center, December 10.

https://www.pewresearch.org/fact-tank/2018/12/10/social-media-outpaces-print-newspapers-in-the-u-s-as-a-news-source

Silverman, Craig (2015). "Lies, damn lies, and viral content. How news websites spread (and debunk) online rumors, unverified claims and misinformation". Tow Center for Digital Journalism.

https://academiccommons.columbia.edu/doi/10.7916/D8Q81RHH

Smith, Aaron; Anderson, Monica (2018b). Social media use in 2018. Pew Research Center.

http://assets.pewresearch.org/wp-content/uploads/sites/14/2018/03/01105133/PI_2018.03.01_Social-Media_FINAL.pdf

Southwell, Brian G.; Thorson, Emily A.; Sheble, Laura (eds.) (2018). Misinformation and mass audiences. Austin: University of Texas Press. ISBN: 9781477314562

Sullivan, Margaret (2017). "It's time to retire the tainted term 'fake news'". Washington Post, January 8. https://www.washingtonpost.com

Tally, Robert (2011). "I am the mainstream media (and so can you!)". In: Amarasingam, Amarnath (ed.). The Stewart/ Colbert effect. Essays on the real impacts of fake news. North Carolina: McFarland, pp. 149-163. ISBN: 9780786458868

Tandoc, Edson C.; Lim, Zheng-Wei; Ling, Richard (2018). “Defining 'fake news'”. Digital journalism, v. 6, n. 2, pp. $137-153$. https://doi.org/10.1080/21670811.2017.1360143

Tapscott, Don (1998). Growing up digital: The rise of the net generation. New York: McGraw-Hill. ISBN: 9780071347983

Thornton, Brian (2000). "The Moon hoax: Debates about ethics in 1835 New York newspapers". Journal of mass media ethics, v. 15, n. 2, pp. 89-100.

https://doi.org/10.1207/S15327728JMME1502_3

Volkoff, Vladimir (2000). Pequena história da desinformação. Lisboa: Editorial Notícias. ISBN: 9789724611556

Wardle, Claire; Derakhshan, Hossein (2017). Information disorder. Toward an interdisciplinary framework for research and policymaking. Council of Europe report DGI(2017)09.

https://rm.coe.int/information-disorder-toward-an-interdisciplinary-framework-for-researc/168076277c

Wineburg, Sam; McGrew, Sarah (2016). "Why students can't google their way to the truth: Fact-checkers and students approach websites differently". Education week, November, 1.

https://www.edweek.org/ew/articles/2016/11/02/why-students-cant-google-their-way-to.html

Woodrow, Alain (1996). Informação, manipulação. Lisboa: Dom Quixote. ISBN: 9789722009300 